\title{
Effectiveness of WhatsApp for measuring migration in follow-up phone surveys. Lessons from a mode experiment in two low-income countries during COVID contact restrictions
}

\author{
Felix Ndashimye+; Oumarou Hebie+, Jasper Tjaden ${ }^{++}$
}

\begin{abstract}
Phone surveys have increasingly become important data collection tools in developing countries, particularly in the context of sudden contact restrictions due to the COVID-19 pandemic. Phone surveys offer particular potential for migration scholars aiming to study cross-border migration behavior. Geographic change of location over time complicates the logistics of face-to-face surveys and heavily increases costs. There is, however, limited evidence of the effectiveness of the phone survey modes in different geographic settings more generally, and in migration research more specifically. In this field experiment, we compared the response rates between WhatsApp-a relatively new but increasingly important survey mode-and interactive voice response (IVR) modes, using a sample of 8446 contacts in Senegal and Guinea. At 12\%, WhatsApp survey response rates were nearly eight percentage points lower than IVR survey response rates. However, WhatsApp offers higher survey completion rates, substantially lower costs and does not introduce more sample selection bias compared to IVR. We discuss the potential of WhatsApp surveys in low-income contexts and provide practical recommendations for field implementation.
\end{abstract}

\section{Keywords: WhatsApp, survey mode, migration, Covid, phone}

+ Global Migration Data Analysis Centre, International Organization for Migration, Dakar, Senegal.

${ }^{++}$Corresponding author: jasper.tjaden@uni-potsdam.de; Faculty of Economic and Social Sciences, University of Potsdam, Germany.

\section{Acknowledgement:}

The authors would like to thank Frank Laczko and colleagues at the Global Migration Data Center, as well as the IOM country offices in Senegal and Guinea for the invaluable input and support for the design and execution of this study. The authors are also thankful to Jessica Wolff of the Stanford's Immigration Policy Lab for the technical advice to set up the WhatsApp survey. 


\section{Introduction}

In this study, we conduct a mode experiment to test the relative performance of interactive voice response (IVR) versus a WhatsApp survey mode in terms of response probability and sample selection bias using pre-collected samples of phone numbers of potential migrants in Guinea and Senegal.

Phone surveys have increasingly become important data collection tools, especially in developing countries (Dabalen, 2016; Firchow \& Mac Ginty, 2020; Leo et al., 2015; Lupu \& Michelitch, 2018). While studies that rely on phone surveys are increasingly common, studies that compare the effectiveness of the different phone survey modes are still limited (Gibson et al., 2017; Gibson et al., 2019; Leo et al., 2015). Phone surveys may facilitate gathering information on hard-to-reach populations and reduce costs given lower demands on staffing and field logistics compared to face-to-face enumeration (Vehovar et al., 2010). Web surveys also have large cost advantages (Daikeler et al., 2020), however, are often not feasible in low-income contexts given low literacy rates (the literacy rates in Guinea and Senegal are $40 \%$ and $51 \%$, respectively) limited internet connectivity and speed required for web surveys. The use of phone surveys has further surged during the COVID-19 pandemic because of contact restrictions in many countries around the world prevented face-to-face enumeration.

Phone surveys also offer much potential for migration scholars aiming to study (crossborder) mobility. While changing the location of residence exacerbates the challenges of data collection in conventional, face-to-face data collection, phone surveys do not depend on location changes to the same extent given that many respondents keep the same phone number after moving within the same country - and in the case of WhatsApp even internationally. The messaging service WhatsApp potentially offers additional advantages for remote data collection such as reduced costs and improved access. WhatsApp has grown to be the most popular messaging app worldwide, being accessed by two billion people every month (Fei et al., 2020).1 However, its use has only recently been explored (Fei et al., 2020; Gruchy et al., 2021; UNDP, 2018). In addition to low cost and coverage, WhatsApp may offer

\footnotetext{
${ }^{1}$ https://www.statista.com/statistics/258749/most-popular-global-mobile-messenger-apps/
} 
advantages in low-income countries with low literacy rates because audio messages can be used.

For migration scholars, WhatsApp is of particular interest as survey respondents may change their telephone provider and phone number when leaving the country, however, continue using their WhatsApp profile. Collecting longitudinal data on migration behavior is often challenging because migrants change locations or may prefer not to be identified, especially if they migrated or intend to migrate irregularly (Liu et al., 2016).

The evidence on the effectiveness of phone survey modes in developing countries is scarce (Greenleaf et al., 2017), particularly regarding the use of WhatsApp. Moreover, there is a striking lack of evidence on the effectiveness of phone surveys in measuring cross-border mobility. This study aims to contribute an empirical account to address the gap in the evidence base for phone surveys using WhatsApp, especially in the context of geographic mobility. In this experimental study, we tested the effectiveness of WhatsApp relative to the established method of interactive voice response (IVR). The IVR mode consists of sending pre-recorded audio questions to respondents that respond via the number pad or by responding with simple audio responses.

We conducted a phone follow-up survey based on two non-probability samples that were collected independently from each other in 2018 and 2019 by the International Organization for Migration to study the impact of its information campaigns on irregular migration in Guinea and Senegal (Bia-Zafinikamia et al., 2020; Dunsch et al., 2019; Tjaden \& Dunsch, 2021; Tjaden \& Gninafon, 2021). The pooled sample included 8,446 respondents covering rural (northwestern Guinea; $\mathrm{N}=2,144$ ) and urban contexts (Dakar, Senegal; N=6,899). We conducted the follow-up phone survey 12-16 months after last contact with the sample population. We randomly assigned the phone contacts to be surveyed by either IVR or WhatsApp.

The main interest of this study is to examine the effect of using WhatsApp on unit nonresponse. 2,144 respondents in the two samples used for the follow-up phone survey had WhatsApp installed on their phones. All respondents without WhatsApp received the IVR mode. To make use of the remaining respondents without WhatsAPP $(\mathrm{N}=6.214)$, we tested 
the effects of providing small monetary incentives (see Figure 1 for a sample graphical illustration). The role of incentives in phone surveys has been addressed in the literature (e.g. Morello \& Leo, 2016), therefore we focus the study on the results of the WhatsApp experiment and limit the discussion on incentives to briefly reporting the results.

This study, thus, sought to answer three main questions:

1. Is WhatsApp more effective in terms of unit non-response than IVR survey modes in the context of follow-up phone surveys in low-income countries?

2. Do different survey modes introduce different selection bias in survey participation relative to the base sample?

3. How do WhatsApp and IVR compare in terms of cost-effectiveness (i.e. relative unit costs for completed surveys in the follow-up survey)?

This study makes two main contributions to the literature: First, while a limited number of studies have tested the use of WhatsApp (Fei et al., 2020; Gruchy et al., 2021), we are unaware of any study that has compared WhatsApp to other automated phone survey modes such as IVR or SMS. To the best of our knowledge, we are also the first to use WhatsApp voice notes, which are particularly popular in developing countries as compared to regular WhatsApp texts. The advantage of voice notes is that even individuals with limited reading and writing ability can respond to the survey. ${ }^{2}$ Moreover, the ability to send and receive long messages without spending a lot of internet credits makes WhatsApp voice notes popular in countries where the internet is often expensive and unreliable. We chose to use voice notes to ensure that the survey format was similar for WhatsApp and IVR. Like in IVR surveys, respondents were sent audio questions to which they replied by sending a number that corresponded to their answer.

Second, we also tested the extent to which WhatsApp and IVR survey modes suffer from two important concerns in phone surveys: Sample selection bias introduced by unit nonresponse (attrition) (Leeuw \& Berzelak, 2016). This is important because, for example, we may find different responses on migration intentions and behavior between WhatsApp and

\footnotetext{
${ }^{2}$ The Economist. (2019). How WhatsApp is used and misused in Africa. Available at: https://www.economist.com/middle-east-and-africa/2019/07/18/how-whatsapp-is-used-and-misused-in-africa
} 
IVR survey if, for example, younger respondents are more likely than older respondents to respond via WhatsApp than via IVR.

The results are a cautionary tale. Both WhatsApp and IVR survey modes yield modest response rates (6-20\% depending on the country), but IVR respondents are more likely than WhatsApp respondent to start and complete the survey. However, WhatsApp users are more likely to finish the survey conditional on starting compared to responders contacted through IVR. Furthermore, comparing baseline characteristics with characteristics in the respondents who participated in the follow-up phone survey, we do not find any evidence that WhatsApp introduces sample selection issues in relation to age, gender, and education relative to IVR. We also find that WhatsApp performed worse in Guinea - where we used a rural sample with overall lower WhatsApp penetration - compared to Senegal - where we used an urban sample with high WhatsApp penetration rates and better electricity and internet connectivity. Some respondents in rural areas may have WhatsApp on their phones but are less likely to respond to a survey because they do not commonly use the app in their day-to-day life or have worse internet connectivity. Oppositive to expectations, WhatsApp did not offer advantages in terms of measuring (cross-border) migration. While WhatsApp performs slightly worse relative to IVR, it offers substantial cost advantages. Finally, we find no evidence that incentives boost IVR survey completion rates.

In addition to results from survey mode experiments, the study also provides several practical lessons regarding implementation of WhatsApp surveys which may further increase response rates. Given the novelty of WhatsApp surveys, we hope that future studies may benefit from this experience.

\section{Previous research}

\subsection{Previous evidence on relative effectiveness of survey modes in follow-up phone surveys}

In light of poor quality of traditional data sources such as censuses and administrative data in developing countries (Jerven \& Johnston, 2015), new opportunities based on mobile phone surveys receive much excitement in the survey methods community. Phone surveys 
have increased in popularity given the rapid growth in access to cell phones over the recent years: in Sub-Saharan Africa, nearly 9 in 10 people currently own a mobile phone (The World Bank, 2021). In addition to lowering the costs relative to face-to-face household surveys (Dabalen, 2016; Dillon, 2012; Leo et al., 2015; Schuster \& Perez Brito, 2011), phone surveys modes such as computer-assisted telephone interviewing (CATI), SMS, IVR, and WhatsApp can be used to collect data on populations that are in conflict zones or areas that are geographically hard to reach (Firchow \& Mac Ginty, 2020). Some work has found that phone surveys are as reliable as other modes including mail-in surveys and internet opt-in surveys (Ansolabehere \& Schaffner, 2014; Lee et al., 2019). Lynn and Kaminska (2013) find mobile phone surveys comparable to landline CATI surveys in terms of response rates. In the same vein, Garlick et al. (2020) find that high-frequency phone surveys do not substantially affect data quality.

WhatsApp surveys, especially, offer several opportunities because, unlike other phone survey modes that rely on active phone numbers, WhatsApp users can keep their accounts anywhere in the world (Fei et al., 2020). WhatsApp is currently the most popular messaging app worldwide, being accessed by two billion people every month (Fei et al., 2020). ${ }^{3}$ In addition, in WhatsApp text or audio surveys, respondents can choose when to respond based on their own schedule. IVR calls require immediate responses when the call takes place, otherwise, unanswered calls lead to multiple contact attempts.

While studies that rely on phone surveys are increasingly common, studies that compare the effectiveness of the different phone survey modes are still limited (Gibson et al., 2017; Gibson et al., 2019; Leo et al., 2015). Yet, response rates can vary significantly between different modes, as well as in different contexts. For example, in a phone survey on voting behavior in Nigeria, Lau et al. (2019) found $0.2 \%$ and 3\% response rates for SMS and IVR surveys, respectively. In contrast, in Ghana and Liberia, researchers used IVR surveys to screen valid phone numbers from a list of randomly generated numbers and found response rates of $31 \%$ and 52\%, respectively (L'Engle et al., 2018; Maffioli, 2020). In Burkina Faso, a "hybrid IVR

\footnotetext{
${ }^{3}$ Tankovska, H., “Most Popular Global Mobile Messaging Apps,” Technical Report 2021.
} 
survey" that involved a real person introducing the survey before the automated calls were launched yielded a response rate of nearly 20\% (Greenleaf et al., 2020). IVR surveys in other low-income countries have yielded response rates that range between $8 \%$ and $40 \%$ (see Gibson et al., 2019 for list of examples).

Providing incentives is often suggested as one way of increasing response rates, however, prior studies have found mixed evidence. While the literature generally suggests positive effects of incentives (Gibson et al., 2017; Gibson et al., 2019; Leo et al., 2015; Morello \& Leo, 2016), studies that were conducted in several low-income countries found large impacts of airtime incentives on responses rates in some countries and inconclusive or limited impacts in other countries (Ballivian et al., 2015; Leo et al., 2015). In fact, in South Sudan, Demombynes et al. (2013) found that larger incentives discouraged participation in the survey as compared to smaller incentives. There have also been instances where incentives were found to influence respondents' answers (e.g. Stecklov et al., 2018). Given the mixed evidence, we included an experiment to test the impact of incentives on response rates in our context.

Despite the advantages of phone surveys, there have been concerns over data quality. The existing literature is inconclusive about which automated survey mode produces lower levels of sample selection bias. For example, Lau et al. (2019) found that several survey modes, including IVR and SMS underrepresented some groups such as older people, women, the less educate and rural residents. The authors also found that IVR respondents were more likely than SMS respondents to give biased responses relative to national estimates. Contrarily, Ballivian et al. (2015) found that IVR responses were more reliable relative to SMS responses. Mixed evidence on response rates and response bias regarding various mobile phone survey modes make it difficult for researchers to make inevitable tradeoffs when implementing surveys in the field (Vehovar et al., 2010).

To expand the existing literature on sample selection introduced by various modes, we tested the extent to which IVR and WhatsApp modes affect the correlation between survey responses and respondents' socio-demographic characteristics.

\subsection{Measuring cross-border mobility}


Measuring international migration through surveys presents a long-standing challenge to social scientists (Bilsborrow et al., 1997; Willekens et al., 2016). Longitudinal, so-called 'tracing' surveys are the gold-standard in measuring international migration behaviour (Beauchemin \& Schoumaker, 2016). This design allows researchers to collect responses from the same individuals over time and across different geographic locations before, during and after the process of migration. A longitudinal survey allows researchers to analyse individual level factors driving migration and how changes across life can affect migration. Most importantly, longitudinal studies are the only way to verify whether an individual actually migrated and where they migrated to. Achieving low panel dropout (i.e. attrition; unit non-response at endline) is a major challenge in longitudinal migration surveys. Baseline respondents may not be reachable after relocating abroad. In the context of irregular migration, respondents may actively avoid being re-interviewed and located. Panel dropout may bias effect estimates and, in the case of migration, it is often impossible to distinguish out-migration from other reasons for dropping out from the survey (Rindfuss et al., 2007). ${ }^{4}$

New technologies have entered the scene offering a potential avenue to improve the feasibility of prospective longitudinal migration surveys by dramatically reducing the costs (Jacobsen \& Kühne, 2021). WhatsApp, in particular, has many characteristics that make it potentially appealing for migration researchers. Most importantly, it is entirely free and its use is almost universal in many countries. New approaches facilitate the automation of WhatsApp surveys and reduce implementation hurdles (Fei et al., 2020). In addition, unlike SMS and call surveys, WhatsApp users may continue using their profile after migrating abroad because their account does not rely on mobile network providers who are usually bounded to individual countries.

\footnotetext{
${ }^{4}$ As a result of the difficulty of implementing longitudinal migration surveys, in particular the high cost of keeping attrition low, many researchers have favoured alternative approaches such as general household surveys in countries of origin where family members provide information on migration of other household members or retrospective panel surveys where immigrants in destination countries are interviewed about their migration history Bilsborrow et al. (1997); Liu et al. (2016). However, both have serious drawbacks. Using household members as proxies introduces bias given that information could be imprecise or incomplete. Retrospective surveys suffer from re-call bias and usually are based on selective samples of particular migrants (that successfully migrated and reside legally in the country).
} 
However, research on survey modes to reduce attrition using text messages, WhatsApp messages, WhatsApp audio messages, online surveys and phone calls is relatively scarce and the available evidence shows mixed results. In this study, we assess the effectiveness WhatsApp phone survey modes in the context of a migration to gain new insights on whether WhatsApp provides additional value to migration scholars.

\section{Data \& Methods}

\subsection{Sample}

This study tests the effectiveness of using WhatsApp and IVR survey modes in combination with monetary incentives on response rates, using two samples of respondents collected in Dakar, Senegal, and North-Western regions of Guinea, approximately one year prior. Samples were originally collected in the context of two impact evaluation studies on the effect of IOM's awareness raising campaigns on the risks of irregular migration in Senegal and Guinea. The main aim of the initial study was to measure the knowledge, perceptions, attitudes and intentions among potential migrants (Bia-Zafinikamia et al., 2020; Dunsch et al., 2019; Tjaden \& Dunsch, 2021; Tjaden \& Gninafon, 2021). The studies were designed as randomized field experiments with two waves of data collection (baseline and endline).

Both studies were conducted using face-to-face surveys in 2018 and 2019. At baseline, the research team collected phone numbers from approximately 11,000 respondents. The respondents provided their primary, secondary, and third phone numbers to facilitate future correspondence and follow-up.

In Senegal, the research team recruited 8,446 potential migrants from eight neighborhoods in Dakar aged between 15 and 40 years for a study on the impact of the Migrants as Messengers (MaM) campaign ${ }^{5}$ on the knowledge, risks, and intentions related to irregular migration. Using a randomized controlled trial (RCT) approach, the study assigned the participants to either treatment group or a control group. Those in the treatment group were

\footnotetext{
${ }^{5}$ https://publications.iom.int/system/files/pdf/migrants_as_messengers_senegal.pdf
} 
shown a documentary film about the dangers of irregular migration whereas the control group was shown a film unrelated to migration (Dunsch et al., 2019; Tjaden \& Dunsch, 2021). In Guinea, 2,800 potential migrants between the ages 15 and 39 were recruited from 63 villages to participate in a study on the impact of Cinemarena campaign ${ }^{6}$ on the knowledge, risks, and intentions related to irregular migration. The campaign consisted of a mobile cinema caravan which visited 32 villages in the treatment group showing documentary films about the risks and dangers of irregular migration in selected villages. For each treated village, the research team selected a control village where the film was not shown (nontreated village) for comparison (Bia-Zafinikamia et al., 2020; Tjaden \& Gninafon, 2021). Both samples were cleaned and pooled to serve as the basis for randomly assigning survey modes and re-contacting participants one year after the face-to-face interview (see Figure 1 for graphical illustration of the study design).

In addition to phone numbers, the dataset includes information on respondents' demographic characteristics (e.g., gender, age). We limited additional characteristics to age and gender to boost the sample size by including individuals who were initially recruited for the baseline but did not participate. For these non-participants, only age, gender, and phone number are available.

We used automatic reports from the telecom providers to identify the phone numbers that were no longer active. Based on the reports, about $4 \%$ and $9 \%$ of the phone numbers in Guinea and Senegal, respectively, were inactive when the calls were made (i.e. the numbers were not active in the network). For WhatsApp, the call logs showed that about $18 \%$ of all contacts (31\% in Guinea and 17\% in Senegal) 'failed' and were, therefore, not included in the analysis. The large difference between Guinea and Senegal in terms of WhatsApp availability is partly explained by the context in which the sample was collected. The Senegal sample was collected in the capital city Dakar while the Guinean sample was collected in largely rural Northwestern regions.

\footnotetext{
${ }^{6}$ https://publications.iom.int/system/files/pdf/guinea-cinemarena-report-2020.pdf
} 
As shown in Table 1, about 18 per cent of the respondents are female. The proportion of women was higher in Senegal (19\%) relative to Guinea (15\%). The average age was about 24 across both countries and most of the respondents are educated: $61 \%$ in Guinea and 51\% in Senegal had a high school degree or more.

Although WhatsApp is currently the most popular messaging app worldwide, access to the app varies by country due to factors such as internet access and rate of smartphone ownership. For example, in our setting, the rate of WhatsApp subscription in Senegal was about 30\%, which was three times higher than the rate in Guinea.

\subsection{Experimental design}

We tested the effects of various phone survey modes on response probability in a survey one year after last contact. The survey questions were related to migration intentions and behaviour. We split all respondents in two groups. Group 1 testes the relative effectiveness of WhatsApp vs. IVR. Group 2 tested the effect of incentives (see Figure 1 for graphical illustration). The underlying sample of phone contacts combined two different contexts: In Guinea, the respondents were largely based in rural settings whereas respondents in Senegal were based in exclusively urban settings. We first stratified the sample by treatment status ${ }^{7}$ in the original study (see previous section) and then randomly allocated the phone numbers to the different treatment groups. We tested the survey modes in the two settings separately because rural residents are often underrepresented in phone surveys due to low phone ownership (Lau et al., 2019), yet the factors that influence survey response rates (e.g. education) vary between rural and urban settings.

\section{Group 1: WhatsApp vs IVR}

To compare WhatsApp and IVR response rates, we first identified respondents in our sample who have WhatsApp installed on their phones. We used a specialized application that

\footnotetext{
${ }^{7}$ The treatment in the original study consisted of an awareness raising campaign (documentary film screenings, discussion).
} 
identifies phone numbers that are registered on WhatsApp from the list of contacts on the phone. ${ }^{8}$ We then randomly assigned those respondents to either the WhatsApp survey mode or the IVR mode. Separating WhatsApp users from non-WhatsApp users is necessary to ensure that the respondents had equal probability of accessing either survey mode. All respondents in the WhatsApp study received an airtime credit equivalent to $\$ 2$ if they completed the survey (regardless of whether they were in the WhatsApp or IVR treatment group. The incentive was necessary because using WhatsApp to answer the survey incurs costs for the respondent by using up mobile data. ${ }^{9}$

We used WhatsApp voice notes, which are particularly popular in developing countries as compared to regular WhatsApp texts. The advantage of voice notes is that even individuals with limited reading and writing ability can respond to the survey. This is important because Guinea and Senegal have some of the lowest adult literacy rates in the world of about $40 \%$ and $51 \%$, respectively. ${ }^{10}$ In addition to broad respondent coverage, we chose to use WhatsApp voice notes to ensure that the mode was as similar as possible to IVR. The IVR mode consists of phone calls that play pre-recorded audio questions to respondents that respond via the number pad or by responding with simple audio responses. In both the WhatsApp and IVR group, all respondents first received a short text message introducing the survey and announcing the survey launch one hour later.

\section{Group 2: IVR with Incentives vs IVR without incentives treatment}

For the remaining sample of respondents, i.e. respondents in the initial sample that do not have WhatsApp installed on their phones, we contribute to available literature by assessing the role of phone credit incentives. While incentives are often used to boost phone survey response rates, evidence of their effectiveness is still mixed. We tested the effectiveness of offering incentives in the form of a small airtime credit when the survey was completed. Respondents were randomly assigned to IVR with incentives or IVR without incentives.

\footnotetext{
${ }^{8}$ We used the "Export Contacts for WhatsApp" app. There are still very few apps that can automatically identify WhatsApp numbers from phone contacts. This app charges about $\$ 7$ to verify long contact lists and export the WhatsApp numbers to a CSV file.

${ }^{9}$ Unlike many high-income countries, many Guineans and Senegalese have pay-by-minute or pay-by-data contracts instead of fixed monthly contracts.

${ }^{10}$ http://uis.unesco.org/en/topic/literacy
} 
Through an SMS, the respondents in the incentives group were promised an airtime credit (equivalent of 2 USD) conditional on completing the survey. The airtime was automatically sent to the eligible recipients right after they completed the survey.

About $13 \%$ of all the respondents had more than one phone number $26 \%$ in Guinea and $8 \%$ in Senegal). Additional numbers were not counted for the random assignment but were used for follow-up contacts with respondents. We adjust response probability models by the number of available phone contacts.

Figure 1: Random assignment of WhatsApp \& non-WhatsApp treatments

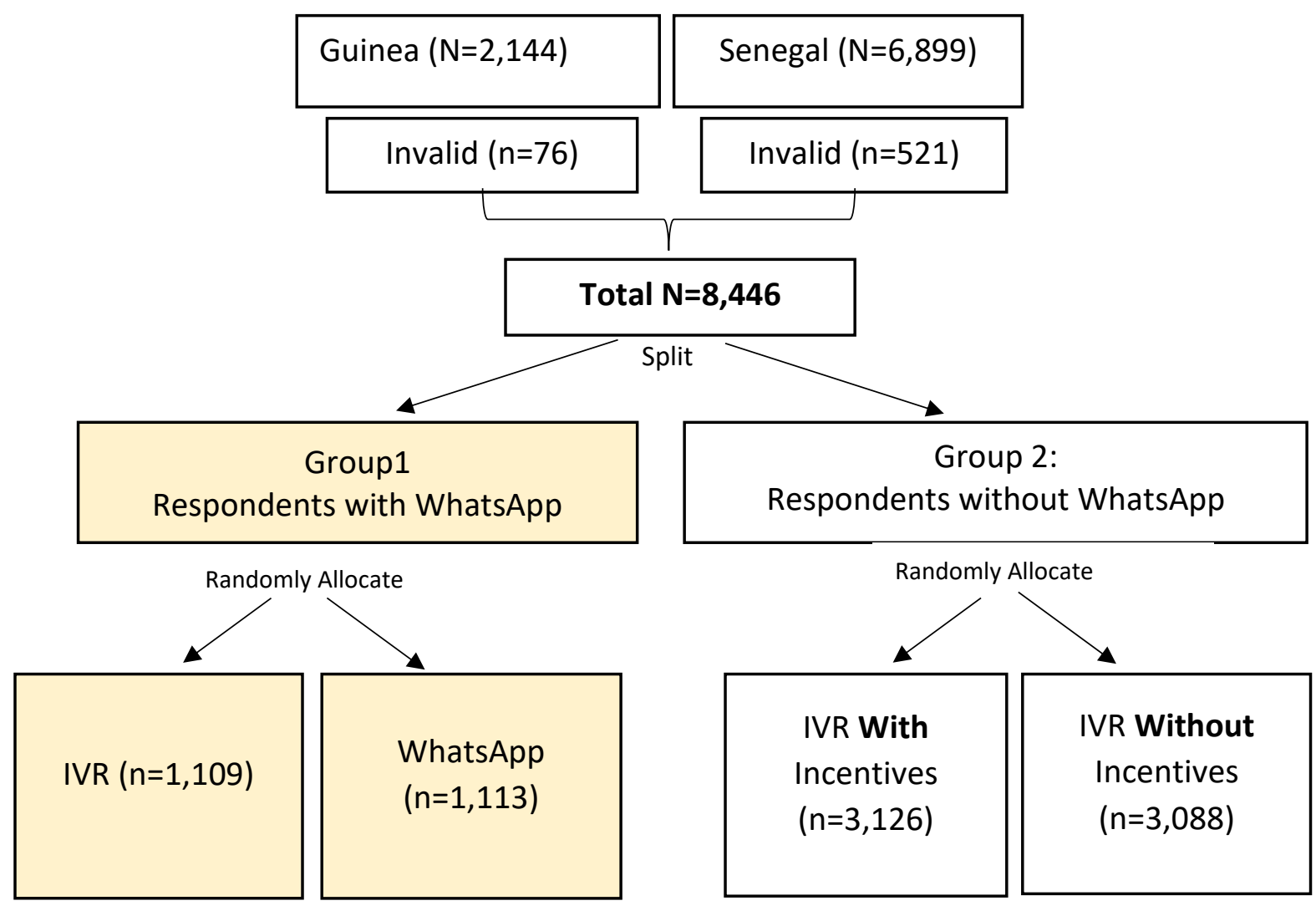

Note: Sample based on data collected by IOM-GMDAC in 2018 and 2019. The phone follow-up survey was conducted in 2021.The phone numbers in each group include engaged and nonengaged respondents. Engaged respondents are those that picked the IVR calls (regardless of whether they responded to the survey) or read the introductory message in WhatsApp. 


\section{The model}

We compared the survey response probability for each experiment using a linear model as follow:

$$
Y_{i}=\delta+\gamma \text { Treat_Arm }{ }_{i}+\beta X_{i}+\theta+\epsilon_{i}
$$

Where $Y_{i}$ is the response status in the phone survey (participated in follow-up phone survey or not), Treat_Arm $i$ is an indicator for the respondent's assignment to either of the two experiments (WhatsApp vs IVR or IVR with incentives vs. IVR without incentives, see Figure 1). The coefficient $\gamma$ is the difference in survey response rates for the corresponding treatment pair. $X_{i}$ is a vector for demographic characteristics for each respondent including age and gender. For the main model, where we combined the two samples, we included a dummy variable for country, $\theta$, to control for unobserved differences between Senegal and Guinea. We then run the models separately for each country to check for robustness.

Randomized experiments generate unbiased estimates to the extent that the observable and unobservable characteristics are equally distributed among the groups being compared. To test the success of the randomization, we estimated the correlation between some key characteristics (gender, age, and education) and the likelihood of being assigned to the various treatment groups. The results showed that there was no co correlation between the characteristics we tested and the treatments (see Table A4 in the Annex).

\subsection{Implementation}

We developed a four-question follow-up survey about the current countries of residence to measure whether somebody has migrated abroad or stayed in Senegal or Guinea as well as migration intentions. We worked with a specialized phone survey provider, EngageSpark, to create the survey on their online platform. The survey questions were translated in local languages that are predominant in the regions where the samples were drawn (Wolof in Senegal and Susu in Guinea). We piloted the survey on 300 randomly selected contacts across all treatment arms to ensure (a) the provider's platform worked as expected and (b) the clarity of the questions. For those that were assigned to the incentives group, the airtime credits were automatically sent through the survey 
platform immediately after they completed the survey. The first- and second-round calls (IVR) and audio messages (WhatsApp) were launched between September 28 and October 3 in 2020 and between February 19-22, 2021.

IVR study

IVR surveys consist of sending pre-recorded automated questions. The audio question includes answer options and instructions on how to respond. The responses are sent by pressing a number that corresponds to the selected option or by responding by speaking. The survey platform automatically compiles all the answers in a file to facilitate the analysis.

We sent an introductory SMS one hour before sending the automated calls. The SMS reminded the recipient that they were being contacted for a follow-up study. The message informed the recipients in the incentives group that they would get an equivalent of $\$ 2$ if they completed the survey. We alternated between workdays and weekends for initial calls and recalls. For each survey round, the respondents were called five times on three different days (e.g. Tuesday-Thursday-Saturday) if they did not initially take the survey. The non-responding contacts were re-called three times on the first day and the calls were made after 15minutes, 30 minutes, and 1 hour ${ }^{11}$. If all the three calls were not answered, one other call was sent on the second and third days. The calls were made between $3 \mathrm{pm}$ and $7 \mathrm{pm}$.

We used automatic reports from the telecom providers to identify valid and invalid calls. For the calls that were not picked, the reports show whether (a) the number was invalid, (b) the phone rung but there was no answer, and (c) whether the phone number was not accessible by the time the call was made. Based on the reports, about 3.5\% and $7.6 \%$ of the phone numbers in Guinea and Senegal, respectively, were invalid when the calls were made. Only $6 \%$ of all numbers were inaccessible during the calls whereas 33\% of the calls (34\% and 31\% in Senegal and Guinea, respectively) went through but none picked for all the five times we sent the calls.

\section{WhatsApp study}

The implementation of the WhatsApp study, on the other hand, was slightly different. Per WhatsApp's policy, sending an automated survey to a large number of contacts requires WhatsApp's special approval and respondent consent. As a result, all respondents who were randomly assigned to the WhatsApp mode first received an introductory text directly in their WhatsApp one hour before the

\footnotetext{
${ }^{11}$ This is the default schedule set by EngageSpark for recalls.
} 
audio messages were sent. The text introduced the researchers' affiliation-IOM, described the goal of the survey, invited the responded to take the survey. We first sent the approved introductory text ${ }^{12}$ directly to the respondent's WhatsApp. The WhatsApp audio message survey could only be launched if the respondent first approved by clicking on the first message received through WhatsApp.

Overall, 64\% (39\% in Guinea and 67\% in Senegal) of the contacts 'read' the introductory text. The contacts that agreed to take the survey received the questions in audio messages iteratively. The respondents could start the survey any time during the week that it was active. Like in IVR surveys, respondents were sent audio questions to which they replied by sending a number that corresponded to their answer. The audio note included a question and a list of answers. To be consistent with the IVR recalls, the WhatsApp survey was repeated.

For WhatsApp, the call logs showed that about $18 \%$ of all intro messages (31\% in Guinea and $17 \%$ in Senegal) 'failed', meaning that they did not reach the recipients. According to EngageSpark, the template message can fail when the number is not on WhatsApp or when the system failed to deliver the message due to various technical reasons. The reports also showed that about $19 \%$ of the intro messages were delivered but were not read or the delivery status was not known.

For the main analyses in this paper, we classified the contacts in two categories based on the reports: engaged and non-engaged contacts. We defined non-engaged contacts as all non-answered calls (IVR) and non-read (WhatsApp) intro messages. Table A6 in the Appendix shows the differences in response rates for the sample of engaged users only.

\section{Results}

\subsection{Comparing survey response and completion rates by survey mode}

Overall, we observed low engagement rates, i.e., the rate at which respondents initially pick up IVR calls or read the WhatsApp introductory message. The average engagement rate for the WhatsApp treatment was higher in Senegal (67\%) than in Guinea (39\%) potentially reflecting the differences in urbanization (rural areas in Guinea, urban centre in Senegal), the app's ownership among the general population, as well as internet access between the

\footnotetext{
${ }^{12}$ A template message is first sent to WhatsApp for approval. Per WhatsApp's policy, the message must reference the sender's prior contact with the recipient to ensure that the recipient has consented to be contacted. We include this message in Appendix 5.
} 
two countries. The engagements rates in IVR, however, were slightly higher in Guinea (80\%) than in Senegal (76\%). For the WhatsApp groups, the response rates (i.e. those who responded to at least one question) were $12 \%$ and $6 \%$ in Senegal and Guinea, respectively. For the IVR groups the response rates were 20\% in Senegal and 16\% in Guinea. Survey completion rates (i.e., those who responded to all survey questions) were much lower in both countries. In Senegal, among those who engaged with the survey, completion rates were $10 \%$ for WhatsApp and $14 \%$ for IVR. In Guinea, among those who engaged with the survey, completion rates were $2 \%$ for WhatsApp and $9 \%$ for IVR. This is likely related to the rural context for the Guinean sample.

For the non-WhatsApp groups, on the other hand, the response rates and completion rates were more comparable between the incentives and non-incentives treatments, as well as between the two countries. For the groups that were offered airtime incentives, overall survey take-up rates were $18 \%$ in Senegal and $14 \%$ in Guinea. These rates were similar to those of non-incentives groups in both countries. Generally, the rates for each outcome are higher in Senegal than in Guinea.

Table 1. Descriptive statistics

\begin{tabular}{lccc}
\hline & $\begin{array}{c}(1) \\
\text { All }\end{array}$ & $\begin{array}{c}(1) \\
\text { Guinea }\end{array}$ & $\begin{array}{c}(3) \\
\text { Senegal }\end{array}$ \\
\hline Age & Mean & Mean & Mean \\
Female & 23.76 & 23.81 & 23.75 \\
Has less than high school & 0.20 & 0.18 & 0.20 \\
Has high school or higher & 0.47 & 0.44 & 0.51 \\
Has WhatsApp & 0.53 & 0.56 & 0.49 \\
Has two phone numbers & 0.26 & 0.08 & 0.32 \\
Overall engagement rate* & 0.13 & 0.26 & 0.08 \\
$\quad$ WhatsApp Group & & & \\
$\quad$ WhatsApp & 0.64 & 0.39 & 0.67 \\
IVR & 0.77 & 0.80 & 0.76 \\
Non-WhatsApp Group & & & \\
IVR-Incentives & 0.59 & 0.75 & 0.52 \\
IVR-no incentives & 0.55 & 0.74 & 0.46 \\
Overall survey response rate** & & & \\
WhatsApp Group & & & \\
WhatsApp & 0.12 & 0.06 & 0.12
\end{tabular}




\begin{tabular}{cccc} 
IVR & 0.19 & 0.16 & 0.20 \\
Non-WhatsApp Group & & & \\
IVR-Incentives & 0.17 & 0.14 & 0.18 \\
$\begin{array}{c}\text { IVR-no incentives } \\
\text { Survey completion Rate*** }\end{array}$ & 0.16 & 0.14 & 0.18 \\
WhatsApp Group & & & \\
WhatsApp & 0.10 & 0.02 & 0.10 \\
IVR & 0.14 & 0.09 & 0.14 \\
Non-WhatsApp Group & & & \\
IVR-Incentives & 0.09 & 0.06 & 0.11 \\
IVR-no incentives & 0.09 & 0.07 & 0.10 \\
\hline Observations & $\mathbf{8 , 4 4 6}$ & $\mathbf{2 , 0 6 8}$ & $\mathbf{6 , 3 7 8}$ \\
\hline
\end{tabular}

Notes: *engagement means that the respondent picked the IVR call or read the introductory message in WhatsApp. ${ }^{* *}$ The overall response rate is calculated based on all contacts who answered at least the first survey question. ${ }^{* * *}$ The completion rate is defined as answering all survey questions. Sample based on data collected by IOM-GMDAC in 2018 and 2019. The phone follow-up survey was conducted in 2021.

\subsubsection{Effect of WhatsApp}

The results in Table 2 show that, overall, respondents are more likely to start and complete IVR surveys than WhatsApp surveys by 7.7 percentage points and 3.8 percentage points, respectively. The smaller gap in completion rates is particularly important because it shows that the share of respondents who started but not completed the survey are much lower for WhatsApp respondents relative to IVR respondents. In Senegal, WhatsApp respondents are less likely than IVR respondents to start and complete the survey by 7.6 percentage points and 3.7, respectively. In Guinea, on the other hand, WhatsApp respondents are less likely to start the survey than IVR respondents by 8.5 percentage points. The IVR-WhatsApp gap in survey completion rates is negative but statistically insignificant.

Table 2. The effect of WhatsApp mode on response probability in the follow-up phone survey

\begin{tabular}{lccc} 
& $(1)$ & $(2)$ & $(3)$ \\
& All & Guinea & Senegal \\
\hline \multicolumn{4}{c}{ Panel I. Overall survey response } \\
Contacted via WhatsApp & $-0.077^{* * *}$ & $-0.085^{*}$ & $-0.076^{* * *}$ \\
(vs. IVR) & & &
\end{tabular}




\begin{tabular}{|c|c|c|c|}
\hline Constant & $\begin{array}{l}0.200^{* * *} \\
(0.038)\end{array}$ & $\begin{array}{l}0.290^{* * *} \\
(0.099)\end{array}$ & $\begin{array}{l}0.191^{* * *} \\
(0.041)\end{array}$ \\
\hline \multicolumn{4}{|c|}{ Panel II. Survey completion } \\
\hline \multirow{2}{*}{$\begin{array}{l}\text { Contacted via WhatsApp } \\
\text { (vs. IVR) }\end{array}$} & $-0.038^{* * *}$ & -0.055 & $-0.037^{* *}$ \\
\hline & $(0.014)$ & $(0.034)$ & $(0.015)$ \\
\hline Constant & $\begin{array}{l}0.130^{* * *} \\
(0.034)\end{array}$ & $\begin{array}{c}0.046 \\
(0.073)\end{array}$ & $\begin{array}{l}0.142^{* * *} \\
(0.037)\end{array}$ \\
\hline$N$ & 2232 & 184 & 2048 \\
\hline \multicolumn{4}{|c|}{$\begin{array}{l}\text { Note: Standard errors in parentheses, }{ }^{*} p<0.1,{ }^{* *} p<0.05,{ }^{* * *} p<0.01 \text {. The sample includes only contacts that } \\
\text { have WhatsApp (see Figure } 1 \text { for details on the study design). The comparison group was contacted via IVR. } \\
\text { Overall response rate includes all contacts that responded to at least the first question. Completion rate } \\
\text { includes all contacts that responded to all questions as expected. Survey mode was randomly assigned and } \\
\text { observable covariates are balanced across groups. However, in all the models, we controlled for age and } \\
\text { gender to improve the precision of the estimated effects. }\end{array}$} \\
\hline
\end{tabular}

\subsubsection{Cost effectiveness}

While WhatsApp surveys have lower responses rates, they are significantly cheaper than IVR surveys. The average cost of a completed WhatsApp survey was about four times and ten times lower than the cost of an IVR survey in Senegal and Guinea, respectively (see Table A5 in the Annex). Additionally, the cost for WhatsApp surveys is standard across all countries whereas the cost for IVR surveys varies by country. Costs involved in IVR surveys mainly consist of the introductory text messages and the automated calls. Text messages are charged based the number of characters whereas the calls are charged per minute. Costs of WhatsApp surveys include standard charges for WhatsApp messages or voice notes and may vary depending on how surveys are implemented, and which providers are used.13

\subsubsection{Effect of incentives}

\footnotetext{
${ }^{13}$ In our context, every delivered voice note and a corresponding response were equally charged $\$ 0.03$ by the provider.
} 
The likelihood of starting the survey for the 'non-incentive' group was 14\% in Guinea and $18 \%$ in Senegal. The offer of incentives did not significantly increase the response rates across the board. Similarly, for survey completion rates, incentives did not have any positive impact (see Table A1 in the Appendix).

\subsubsection{Selection and data quality}

It is possible that different survey modes introduce selection in terms of who participates in the follow-up survey. We tested the extent to which survey takers for each survey mode are representative of the group initially assigned to the mode. We separately regressed each of the key characteristics (gender, age, and education) on the response status in the survey, separately for each survey mode. The effects of individual characteristics and the likelihood of responding to the survey are insignificant for all the treatments. This indicates that there is no correlation between the likelihood of taking the survey and the socio-demographic characteristics for any of the treatments we tested (see Table A4 in the Annex). It has to be noted that the follow-up survey was conducted based on a non-probability sample which is not representative of the general population or the (unknown) population of potential migrants. As a result, we were not able to compare selection bias in relation to common population characteristics.

\subsection{Migration intentions \& behaviour}

As described in section 2, WhatsApp surveys may offer unique advantages for scholars interested in international migration as WhatsApp profiles may remain active even when respondents do not use their old telephone service provider anymore. Accordingly, we examined the consistency and reliability of the responses on migration behavior and intentions. The survey included questions on respondents' current country of residence and intentions to migrate in the next two years (see Table B1 in the Annex). The question on current residence had three answer options: (1) in Senegal/Guinea, (2) in another country in Africa, and (3) in Europe or somewhere else outside of Africa. The third option is particularly important in determining the reliability of the answers; it would be highly unlikely for IVR respondents to receive the calls without having access to the cell phone service in their country or region. WhatsApp users, on the other hand, could still take that survey anywhere in the world if they kept their account and had access to data or internet. 
Essentially, the only way to learn whether some individuals actually migrated out of Africa would be by WhatsApp respondents.

The proportion of respondents who report living outside of Africa is $11 \%$ in Guinea and 6\% in Senegal. Additionally, the proportion of those that report intentions to migrate in the next two years is $55 \%$ in Guinea and $64 \%$ in Senegal (see Table A2 in the Annex). However, the rates vary significantly by survey mode: Overall, WhatsApp respondents report lower migration rates (2\%) than IVR respondents (5\%) (see Figure A1 and Figure A2 in the Annex). This result is puzzling and may suggest that respondents had difficulties responding to this question. However, the measurement error is potentially lower among WhatsApp respondents since they had more time to listen to the questions. In other words, respondents in the IVR treatment who receive a phone call may feel pressured to answer something to a question they did not understand. This pattern is less likely in the WhatsApp mode because respondents can repeat the voice note as many times as they please. The reported rates of intentions to migrate are identical for the treatment arms within the WhatsApp and non-WhatsApp samples.

\subsection{Lessons from the field}

There are three key practical lessons that we learned about developing and conducting WhatsApp and IVR survey in Senegal and Guinea that may provide helpful insights for future projects in similar contexts.

\subsubsection{Identify valid/active}

Identifying valid or active phone numbers prior to launching the survey is a way to create a valid sampling frame and avoid unnecessary expenses. In our context, this step was important because the phone numbers in our sample had been collected over one year prior to launching the survey. We attempted to use automatic reports from telecom companies to identify inactive numbers but the reports were not entirely accurate. We potentially had fewer invalid phone numbers given that we had directly collected the numbers from the respondents. In cases where the numbers are sourced using other techniques such as random digit dialing (RDD), identifying valid numbers should be one of the most important steps for a phone survey. Field implementation also partially challenged the assumption that WhatsApp users retain their numbers and are, thus, better able to be reached in panel surveys. For WhatsApp, the call logs showed that about $18 \%$ of all contacts $31 \%$ in Guinea and 17\% in Senegal) 'failed' and were, therefore, not included in the analysis. 


\subsubsection{Appropriate length of the survey}

Phone surveys can vary in length, but shorter surveys are potentially more successful than longer surveys. In our setting, we found that, conditional on starting the survey, completion rates were $72 \%$ and $86 \%$ for IVR and WhatsApp groups, respectively. Completion rates were lower for IVR even though the survey had four questions and the average length for completed surveys was only 1.38 minutes. It is likely that completion rates could be even lower if the survey took several minutes. This finding may also be indicative of the fact that respondents using WhatsApp can time their responses according to their own schedules. They can also start the survey and complete it at another time which is a key advantage over IVR surveys.

\subsubsection{Identify WhatsApp numbers and set up the WhatsApp survey platform}

Identifying phone numbers that are on WhatsApp before the random allocation to treatment is crucial to increase the likelihood of reaching the right respondents, as well as to reduce survey costs. We used an app ${ }^{14}$ that automatically identifies numbers that are on WhatsApp from the phone's contacts and exports the list in a CSV format at a small fee.

The implementation of WhatsApp surveys also requires a specialized platform. The researcher has the option of directly programming the survey ${ }^{15}$ or using a commercial platform. Either way, the survey platform must connect to a verified Facebook Business account for the respondents to see the identification of the sender (e.g. name of organization). For our study, we were unable to have a Facebook Business account verified in time and sent the WhatsApp surveys without a profile name, which may have marginally lowered response probabilities. Despite prior consent to be re-contacted, some respondents may have doubted the authenticity of the survey if the sender is not immediately recognizable.

\section{Discussion}

Phone surveys are increasingly popular in developing countries due to their relatively low cost and widespread access to cell phones. Low-literacy rates and low internet connectivity make it difficult to implement web surveys. Using phone surveys has also become crucial during the COVID-19

\footnotetext{
${ }^{14}$ We used an app called Export Contacts for WhatsApp. The app is only available on Play Store.

${ }^{15}$ To program the survey, a programing platform such as Twillio is needed. A detailed description is available at https://immigrationlab.org/project/whatsappsurveys/
} 
pandemic when face-to-face enumeration became impossible due to contact restrictions in many countries. However, there is still limited evidence of the effectiveness of the various phone survey modes. Phone surveys are also a promising solution to measuring migration behavior. Panel face-toface surveys in multiple countries are costly, so phone surveys have the potential to facilitate validating movement of individuals across countries at low cost. WhatsApp in particular offers potential benefits since users may continue to use their profiles after leaving the country which is less likely regarding telephone numbers since phone service is usually bounded to individual countries.

In this study, we tested and compared the effectiveness of WhatsApp voice notes and IVR modes in collecting follow-up phone surveys on migration behavior and intentions. The findings can be summarized as follows:

First, we found that that overall, the two phone survey modes yield modest response rates (6-12\% for the WhatsApp treatment and $14-18 \%$ for the IVR treatment depending on the country). Our findings, however, are not uncommon in the literature: response rates can vary between less than 5\% and 40\% (Lau et al., 2019; Leo et al., 2015).

Second, we found that WhatsApp respondents are less likely than IVR respondents to start the survey but more likely to complete it. While IVR may yield twice (Senegal) and three times (Senegal) higher response rates compared to WhatsApp, WhatsApp users are more likely to complete the survey once they started. The IVR gain over WhatsApp in starting the survey may be due to the fact that WhatsApp users can ignore messages from an unrecognized source before they start the survey whereas IVR respondents determine the source of the call immediately after they have answered their phone. For example, the engagement rate for IVR was about seven percentage points higher than for WhatsApp. On the other hand, the WhasApp gain over IVR in completion rates is expected given that the respondents can complete the survey any time and listen to survey questions repeatedly whereas IVR respondent have to answer on the spot. The ability to choose a time when to answer the survey is especially relevant in context with instable phone coverage and limited or irregular internet connectivity. The technical differences are important factors to consider when determining which survey mode to adopt.

Third, the decision whether to use WhatsApp in phone surveys comes with difficult tradeoffs. While the results show that IVR yields more responses, WhatsApp is substantially cheaper. Including all direct and indirect costs related to implementing the survey, WhatsApp was 3 (Senegal) to 10 (Guinea) times cheaper than IVR. The cost advantages are particularly striking in rural settings. 
Fourth, WhatsApp voice notes do not appear to introduce larger sample selection in terms of the age, gender and education compared to IVR. However, the general population that uses WhatsApp is selected relative to the general population, especially by age. This is an important aspect to consider when deciding on the target population for the survey. The mode experiment assessing the effect of WhatsApp was restricted to respondents who have WhatsApp installed in their phone.

Fifth, the general WhatsApp usage in a location is key to assess the likely success of a WhatsApp survey. The results highlighted that WhatsApp response rates were lower in our Guinean sample which largely consisted of rural villages compared to our Senegal sample which was an urban sample. In rural areas, some respondents may have WhatsApp but are using it less because their friends and family in their local environment do not use it. This may be related to overall lower internet connectivity. This may reduce the response rate. Prior feasibility studies are recommended before launching a new WhatsApp survey to assess whether and how target populations use WhatsApp in their daily lives.

Lastly, we find no evidence that WhatsApp offers unique benefits to migration scholars. The result that more respondents provided information on moving outside of Africa in the IVR treatment compared to the WhatsApp treatment requires further research. ${ }^{16}$ This result may be indicative that WhatsApp reduces measurement bias because respondents have more time to respond and can repeat the questions as many times as they like.

One important aspect to consider with WhatsApp surveys are ethical data privacy concerns. In our study, survey respondents were asked for consent to be contacted for follow-up interviews, including via WhatsApp messenger. Consent was requested again before starting the survey. Informed consent is key because WhatsApp is considered personal communication with the close network and contact from unknown senders - more so than anonymous phone calls - may be considered an intrusive invasion of one's privacy.

\footnotetext{
${ }^{16}$ See resources for improving phone surveys in general: Busara Center (2020, May 4). Getting the most out of your SMS survey: Results from an experiment testing the effects of SMS survey design on response rates and patterns. Available at https://medium.com/busara-center-blog/getting-the-most-out-of-your-sms-survey5b0a02bd6562; Kopper, S. \& Sautmann, A. (2020, March). Best Practices for Conducting Phone Surveys. Available at https://www.povertyactionlab.org/blog/3-20-20/best-practices-conducting-phone-surveys; Özler, B. \& Cuevas, P. F. (2019, November). Reducing attrition in phone surveys. https://blogs.worldbank.org/impactevaluations/reducing-attrition-phonesurveys?CID=WBW AL BlogNotification EN EXT
} 
The study faced three key limitations. First, the length of time between the last in-person surveyover one year-and the follow-up, likely reduced the survey response rates. Given the low pick-up rates on the calls, it's likely that some respondents did not view our calls as coming from trusted sources despite the introductory texts we sent. In Senegal and Guinea, phone users are used to receiving multiple texts and calls from random advertisers or scams. Second, for WhatsApp, we were unable to add our organization's name to our profile in the app so that the respondents would easily know the source of the survey. The lack of clear identification potentially led some respondents to distrust the source of the survey. This is important because at least $64 \%$ of the respondents read the template massage but only few of them started the survey. For example, in a WhatsApp survey in the US where the sender was clearly identified and respondents were familiar with the survey (Fei et al., 2020), response rates could be as high as $76 \%$. Third, the initial samples were collected using nonprobability sampling using face-to-face interviews. As such, our results on sample selection bias are related to a non-probability survey at which is highly selected (i.e. not reflective of the general population in Senegal or Guinea). In addition, relying on phone surveys because of COVID-19 contact restrictions meant a mode switch from face-to-face enumeration in the initial baseline survey.

Despite these limitations, the study provides new evidence: WhatsApp did not show the expected potential to drastically increase response rates in two case studies in low-income countries. The viability of WhatsApp depends on the geographical context. Clear advantages such as low costs, broad usage, independence of location, do not necessarily translate into higher survey response or advantages in measuring migration. However, WhatsApp surveys may still be an attractive option for projects which are less reliant on maximizing sample size as well as projects facing cost constraints. Implementing WhatsApp surveys is still new, and our experience has also revealed certain approaches that may further increase response rates such as using profile names. One potential advantage that has not been fully explored in this study is the capacity to easily share location data and audio-visual information via WhatsApp. More research is needed to identify best practices in this field and inform tradeoffs. 


\section{References}

Ansolabehere, S., \& Schaffner, B. F. (2014). Does Survey Mode Still Matter? Findings from a 2010 Multi-Mode Comparison. Political Analysis, 22(3), 285-303. https://doi.org/10.1093/pan/mpt025

Ballivian, A., Azevedo, J. P., \& Durbin, W. (2015). Using Mobile Phones for High-Frequency Data Collection. In Toninelli, D, Pinter, R \& de Pedraza, P (Ed.), Mobile Research Methods: Opportunities and Challenges of Mobile Research Methodologies (pp. 21-39). Ubiquity Press. https://doi.org/10.5334/bar.c

Beauchemin, C., \& Schoumaker, B. (2016). Micro Methods: Longitudinal Surveys and Analyses. In M. J. White (Ed.), International handbook of migration and population distribution (6 $6^{\text {th }} \mathrm{ed}$.). Springer.

Bia-Zafinikamia, M., Tjaden, J., \& Gninafon, H. (2020). The impact of mobile cinema events on potential migrants in Guinea. Impact Evaluation Report. International Organization for Migration.

Bilsborrow, R. E., Hugo, G., \& Oberai, A. S. (1997). International migration statistics: Guidelines for improving data collection systems (1. publ). ILO.

Dabalen, A. (2016). Mobile Phone Panel Surveys in Developing Countries: A Practical Guide for Microdata Collection (Online-Ausg). World Bank E-Library Archive. The World Bank. https://doi.org/10.1596/978-1-4648-0904-0

Daikeler, J., Bošnjak, M., \& Lozar Manfreda, K. (2020). Web versus other survey modes: an updated and extended meta-analysis comparing response rates. Journal of Survey Statistics and Methodology, 8(3), 513-539.

Demombynes, G., Gubbins, P., \& Romeo, A. (2013). Challenges and Opportunities of Mobile PhoneBased Data Collection: Evidence from South Sudan. World Bank Policy Research Working(6321). https://ssrn.com/abstract=2202683

Dillon, B. (2012). Using mobile phones to collect panel data in developing countries. Journal of International Development, 24(4), 518-527. https://doi.org/10.1002/jid.1771

Dunsch, F., Tjaden, J., \& Quiviger, W. (2019). Migrants as Messengers: The Impact of Peer-to-Peer Communication on Potential Migrants in Senegal. Impact Evaluation Report. International Organization for Migration (IOM).

Fei, J., Wolff, J. S., Hotard, M., Ingham, H., Khanna, S., Lawrence, D., Tesfaye, B., Weinstein, J., Yasenov, V., \& Hainmueller, J. (2020). Automated Chat Application Surveys Using WhatsApp. SocArXiv J9a2y(SocArXiv j9a2y).

Firchow, P., \& Mac Ginty, R. (2020). Including Hard-to-Access Populations Using Mobile Phone Surveys and Participatory Indicators. Sociological Methods \& Research, 49(1), 133-160. https://doi.org/10.1177/0049124117729702

Garlick, R., Orkin, K., \& Quinn, S. (2020). Call Me Maybe: Experimental Evidence on Frequency and Medium Effects in Microenterprise Surveys. The World Bank Economic Review, 34(2), 418443. https://doi.org/10.1093/wber/lhz021

Gibson, D. G., Pereira, A., Farrenkopf, B. A., Labrique, A. B [Alain B.], Pariyo, G. W [George W.], \& Hyder, A. A [Adnan A.] (2017). Mobile Phone Surveys for Collecting Population-Level 
Estimates in Low- and Middle-Income Countries: A Literature Review. Journal of Medical Internet Research, 19(5), e139. https://doi.org/10.2196/jmir.7428

Gibson, D. G., Wosu, A. C., Pariyo, G. W [G. W.], Ahmed, S [S.], Ali, J., Labrique, A. B [A. B.], \& Hyder, A. A [A. A.] (2019). Effect of airtime incentives on response and cooperation rates in non-communicable disease interactive voice response surveys: randomised controlled trials in Bangladesh and Uganda. BMJ Global Health, 4(5).

Greenleaf, A. R., Gadiaga, A., Choi, Y., Guiella, G., Turke, S., Battle, N., Ahmed, S [Saifuddin], \& Moreau, C. (2020). Automated and Interviewer-Administered Mobile Phone Surveys in Burkina Faso: Sociodemographic Differences Among Female Mobile Phone Survey Respondents and Nonrespondents. JMIR MHealth and UHealth, 8(7), e17891. https://doi.org/10.2196/17891

Greenleaf, A. R., Gibson, D. G., Khattar, C., Labrique, A. B [Alain B.], \& Pariyo, G. W [George W.] (2017). Building the Evidence Base for Remote Data Collection in Low- and Middle-Income Countries: Comparing Reliability and Accuracy Across Survey Modalities. Journal of Medical Internet Research, 19(5), e140. https://doi.org/10.2196/jmir.7331

Gruchy, T. de, Vearey, J., Opiti, C., Mlotshwa, L., Manji, K., \& Hanefeld, J. (2021). Research on the move: Exploring WhatsApp as a tool for understanding the intersections between migration, mobility, health and gender in South Africa. Globalization and Health, 17(1), 71. https://doi.org/10.1186/s12992-021-00727-y

Jacobsen, J., \& Kühne, S. (2021). Using a Mobile App When Surveying Highly Mobile Populations: Panel Attrition, Consent, and Interviewer Effects in a Survey of Refugees. Social Science Computer Review, 39(4), 721-743. https://doi.org/10.1177/0894439320985250

Jerven, M., \& Johnston, D. (2015). Statistical Tragedy in Africa? Evaluating the Data Base for African Economic Development. The Journal of Development Studies, 51(2), 111-115. https://doi.org/10.1080/00220388.2014.968141

Lau, C. Q., Cronberg, A., Marks, L., \& Amaya, A. (2019). In Search of the Optimal Mode for Mobile Phone Surveys in Developing Countries. A Comparison of IVR, SMS, and CATI in Nigeria. Survey Research Methods, 13(3), 305-318. https://doi.org/10.18148/srm/2019.v13i3.7375 (305-318 Pages / Survey Research Methods, Vol 13 No 3 (2019)).

Lee, H., Kim, S., Couper, M. P., \& Woo, Y. (2019). Experimental Comparison of PC Web, Smartphone Web, and Telephone Surveys in the New Technology Era. Social Science Computer Review, 37(2), 234-247. https://doi.org/10.1177/0894439318756867

Leeuw, E. D. de, \& Berzelak, N [N.]. (2016). Survey Mode or Survey Modes? In C. Wolf, D. Joye, \& Smith, T. W., Fu, Y.-C. (Eds.), The Sage Handbook of Survey Methodology. Sage.

L’Engle, K., Sefa, E., Adimazoya, E. A., Yartey, E., Lenzi, R., Tarpo, C., Heward-Mills, N. L., Lew, K., \& Ampeh, Y. (2018). Survey research with a random digit dial national mobile phone sample in Ghana: Methods and sample quality. PloS One, 13(1), e0190902. https://doi.org/10.1371/journal.pone.0190902

Leo, B., Morello, R., Mellon, J., Peixoto, T., \& Davenport, S. T. (2015). Do Mobile Phone Surveys Work in Poor Countries? SSRN Electronic Journal. Advance online publication. https://doi.org/10.2139/ssrn.2623097

Liu, M.-M., Creighton, M. J., Riosmena, F., \& Baizán Mun Oz, P. (2016). Prospects for the Comparative Study of International Migration using quasi-longitudinal micro-data. Demographic Research, 35, 745-782. https://doi.org/10.4054/DemRes.2016.35.26 
Lupu, N., \& Michelitch, K. (2018). Advances in Survey Methods for the Developing World. Annual Review of Political Science, 21(1), 195-214. https://doi.org/10.1146/annurev-polisci$\underline{052115-021432}$

Lynn, P., \& Kaminska, O. (2013). The impact of mobile phone on survey measurement error. The Public Opinion Quarterly, 77(2), 586-605. http://www.jstor.org/stable/24545755

Maffioli, E. M. (2020). Collecting Data During an Epidemic: A Novel Mobile Phone Research Method. Journal of International Development, 32(8), 1231-1255. https://doi.org/10.1002/jid.3515

Morello, R., \& Leo, B. (2016). Practical Considerations with Using Mobile Phone Survey Incentives: Experiences in Ghana and Tanzania. https://www.cgdev.org/sites/default/files/practicalconsiderations-using-mobile-phone-survey-incentives-ghana-tanzania.pdf

Rindfuss, R. R., Kaneda, T., Chattopadhyay, A., \& Sethaput, C. (2007). Panel studies and migration. Social Science Research, 36(1), 374-403. https://doi.org/10.1016/j.ssresearch.2006.03.005

Schuster, C., \& Perez Brito, C. (2011). Cutting Costs, Boosting Quality and Collecting Data Real-Time : Lessons from a Cell Phone-Based Beneficiary Survey to Strengthen Guatemala's Conditional Cash Transfer Program (No. 166). World Bank.

Stecklov, G., Weinreb, A., \& Carletto, C. (2018). Can incentives improve survey data quality in developing countries? results from a field experiment in India. Journal of the Royal Statistical Society: Series a, 181(4), 1033-1056. https://doi.org/10.1111/rssa.12333

Tjaden, J., \& Dunsch, F. (2021). The effect of peer-to-peer risk information on potential migrants Evidence from a randomized controlled trial in Senegal. World Development, 145, 105488. https://doi.org/10.1016/i.worlddev.2021.105488

Tjaden, J., \& Gninafon, H. (2021). Raising awareness about the risk of irregular migration - Quasiexperimental evidence from Guinea. Population and Development Review(forthcoming).

UNDP. (2018). WhatsApp surveying guide: Lessons learned from two qualitative WhatsApp surveys in Lebanon.

Vehovar, V., Berzelak, N [Nejc], \& Lozar Manfreda, K. (2010). Mobile Phones in an Environment of Competing Survey Modes: Applying Metric for Evaluation of Costs and Errors. Social Science Computer Review, 28(3), 303-318. https://doi.org/10.1177/0894439309353035

Willekens, F., Massey, D. S., Raymer, J., \& Beauchemin, C. (2016). International migration under the microscope. Science, 352(6288), 897-899. https://doi.org/10.1126/science.aaf6545

The World Bank. (2021). Mobile Cellular Subscriptions (per 100 People). https://data.worldbank.org/indicator/IT.CEL.SETS.P2 


\section{Supplementary Material}

Table A1. The effect of incentives on survey response rates

\begin{tabular}{|c|c|c|c|}
\hline & $\begin{array}{l}\text { (1) } \\
\text { All }\end{array}$ & $\begin{array}{c}(2) \\
\text { Guinea }\end{array}$ & $\begin{array}{c}(3) \\
\text { Senegal }\end{array}$ \\
\hline \multicolumn{4}{|c|}{ Panel I. Overall Response Rate } \\
\hline Contact was offered incentives & $\begin{array}{c}0.008 \\
(0.009)\end{array}$ & $\begin{array}{c}0.003 \\
(0.016)\end{array}$ & $\begin{array}{c}0.010 \\
(0.012)\end{array}$ \\
\hline Constant & $\begin{array}{c}0.152^{* * *} \\
(0.023)\end{array}$ & $\begin{array}{c}0.167^{* * * *} \\
(0.034)\end{array}$ & $\begin{array}{c}0.141^{\text {**** }} \\
(0.030)\end{array}$ \\
\hline \multicolumn{4}{|c|}{ Panel II. Survey Completion Rate } \\
\hline Contact was offered incentives & $\begin{array}{c}0.006 \\
(0.007)\end{array}$ & $\begin{array}{c}-0.010 \\
(0.011)\end{array}$ & $\begin{array}{c}0.013 \\
(0.009)\end{array}$ \\
\hline Constant & $\begin{array}{c}0.095^{* * *} \\
(0.017)\end{array}$ & $\begin{array}{c}0.087^{* * *} \\
(0.024)\end{array}$ & $\begin{array}{c}0.101^{* * *} \\
(0.024)\end{array}$ \\
\hline$N$ & 6193 & 1884 & 4309 \\
\hline
\end{tabular}


Table A2. Responses on Migration Behavior and Intentions

\begin{tabular}{llll}
\hline & All & Guinea & Senegal \\
\hline \% Live in another country outside of Africa & 0.07 & 0.11 & 0.06 \\
Observations & $\mathbf{1 , 3 8 1}$ & $\mathbf{2 7 9}$ & $\mathbf{1 , 1 0 2}$ \\
\% Intend to migrate in next 2 years & 0.63 & 0.55 & 0.64 \\
Observations & $\mathbf{7 9 7}$ & $\mathbf{1 1 2}$ & $\mathbf{6 8 5}$ \\
\hline
\end{tabular}

Notes: \% of respondents that currently live outside of Africa is calculated based on those who respondent to the first survey question. Intention to migrate is calculated for those that responded to the second survey question. 
Table A3. Balance test in some key characteristics

\begin{tabular}{|c|c|c|c|}
\hline & $\begin{array}{l}\text { (1) } \\
\text { All }\end{array}$ & $\begin{array}{c}(2) \\
\text { Guinea }\end{array}$ & $\begin{array}{c}(3) \\
\text { Senegal }\end{array}$ \\
\hline \multicolumn{4}{|c|}{ WhatsApp vs IVR } \\
\hline Female & $\begin{array}{l}-0.021 \\
(0.017)\end{array}$ & $\begin{array}{c}0.021 \\
(0.064)\end{array}$ & $\begin{array}{l}-0.024 \\
(0.018)\end{array}$ \\
\hline Age & $\begin{array}{c}0.050 \\
(0.214)\end{array}$ & $\begin{array}{c}0.535 \\
(0.959)\end{array}$ & $\begin{array}{c}0.009 \\
(0.218)\end{array}$ \\
\hline Respondent has second number & $\begin{array}{l}-0.003 \\
(0.009)\end{array}$ & $\begin{array}{l}-0.041 \\
(0.035)\end{array}$ & $\begin{array}{c}0.000 \\
(0.009)\end{array}$ \\
\hline $\begin{array}{l}\text { Respondent participated IOM's campaigns } \\
\text { in } 2019\end{array}$ & -0.006 & - & 0.001 \\
\hline JVR-incentives vs JVR-r & $\begin{array}{c}(0.016) \\
2222 \\
\text { ncentives }\end{array}$ & $\begin{array}{c}- \\
174\end{array}$ & $\begin{array}{c}(0.014) \\
2048\end{array}$ \\
\hline Female & $\begin{array}{c}0.000 \\
(0.010)\end{array}$ & $\begin{array}{c}0.006 \\
(0.018)\end{array}$ & $\begin{array}{l}-0.002 \\
(0.012)\end{array}$ \\
\hline Age & $\begin{array}{l}-0.039 \\
(0.136)\end{array}$ & $\begin{array}{c}0.011 \\
(0.288)\end{array}$ & $\begin{array}{l}-0.059 \\
(0.149)\end{array}$ \\
\hline Respondent has second number & $\begin{array}{l}-0.001 \\
(0.009)\end{array}$ & $\begin{array}{c}0.001 \\
(0.021)\end{array}$ & $\begin{array}{c}0.000 \\
(0.009)\end{array}$ \\
\hline $\begin{array}{l}\text { Respondent participated IOM's campaigns } \\
\text { in } 2019\end{array}$ & 0.002 & - & 0.011 \\
\hline Observations & $\begin{array}{c}(0.012) \\
6214\end{array}$ & $\begin{array}{c}- \\
1884\end{array}$ & $\begin{array}{c}(0.010) \\
4330\end{array}$ \\
\hline
\end{tabular}

Standard errors in parentheses

${ }^{*} p<0.1,{ }^{* *} p<0.05,{ }^{* * *} p<0.01$

The models test the balance in the characteristics that potentially influence the likelihood of survey-taking between the compared groups. 
Table A4. Sample selection among survey-takers relative to whole sample by survey mode

\begin{tabular}{|c|c|c|c|c|}
\hline & $\begin{array}{c}(1) \\
\text { WhatsApp }\end{array}$ & $\begin{array}{l}(2) \\
\text { IVR }\end{array}$ & $\begin{array}{c}(3) \\
\text { IVR-Incentives }\end{array}$ & $\begin{array}{c}\text { (4) } \\
\text { IVR-No } \\
\text { Incentives }\end{array}$ \\
\hline \multicolumn{5}{|c|}{ Gender } \\
\hline Female & $\begin{array}{c}0.008 \\
(0.024)\end{array}$ & $\begin{array}{c}0.039 \\
(0.029)\end{array}$ & $\begin{array}{c}0.023 \\
(0.017)\end{array}$ & $\begin{array}{c}0.000 \\
(0.017)\end{array}$ \\
\hline Constant & $\begin{array}{l}0.113^{* * *} \\
(0.011)\end{array}$ & $\begin{array}{l}0.185^{* * *} \\
(0.013)\end{array}$ & $\begin{array}{l}0.166^{* * *} \\
(0.008)\end{array}$ & $\begin{array}{l}0.163^{* * *} \\
(0.007)\end{array}$ \\
\hline \multicolumn{5}{|c|}{ Age } \\
\hline Age & $\begin{array}{l}-0.000 \\
(0.002)\end{array}$ & $\begin{array}{l}-0.001 \\
(0.002)\end{array}$ & $\begin{array}{c}0.001 \\
(0.001)\end{array}$ & $\begin{array}{l}-0.001 \\
(0.001)\end{array}$ \\
\hline Constant & $\begin{array}{l}0.115^{* *} \\
(0.046)\end{array}$ & $\begin{array}{l}0.228^{* * *} \\
(0.058)\end{array}$ & $\begin{array}{l}0.146^{* * *} \\
(0.031)\end{array}$ & $\begin{array}{l}0.176^{* * *} \\
(0.030)\end{array}$ \\
\hline \multicolumn{5}{|c|}{ Education } \\
\hline Has high school or more & $\begin{array}{c}0.036 \\
(0.050)\end{array}$ & $\begin{array}{l}-0.091 \\
(0.064)\end{array}$ & $\begin{array}{c}0.014 \\
(0.026)\end{array}$ & $\begin{array}{c}0.038 \\
(0.026)\end{array}$ \\
\hline Constant & $\begin{array}{l}0.091^{* * *} \\
(0.033)\end{array}$ & $\begin{array}{l}0.250^{* * *} \\
(0.046)\end{array}$ & $\begin{array}{l}0.151^{* * *} \\
(0.019)\end{array}$ & $\begin{array}{l}0.134^{* * *} \\
(0.019)\end{array}$ \\
\hline Observations & 159 & 158 & 812 & 791 \\
\hline
\end{tabular}

Standard errors in parentheses

${ }^{*} p<0.1,{ }^{* *} p<0.05,{ }^{* * *} p<0.01$

Balance in individual characteristics between survey-takers and non-takers for each survey mode. These models test whether some survey modes systematically attract respondents with specific characteristics relative to the whole sample for the survey mode. 
Table A5. Completed surveys and Cost (in USD)

\begin{tabular}{lcccc}
\hline Group & $\begin{array}{l}\text { Total } \\
\text { contacts } \\
\text { Made }\end{array}$ & $\begin{array}{l}\text { All } \\
\text { Surveys } \\
\text { attempted }\end{array}$ & $\begin{array}{l}\text { Completed } \\
\text { Surveys }\end{array}$ & $\begin{array}{l}\text { Average } \\
\text { Cost per } \\
\text { completed } \\
\text { Survey* }\end{array}$ \\
\hline IVR & \multicolumn{2}{c}{ Senegal } & & \\
WA & 7,596 & 1,225 & 752 & 1.40 \\
IVR & 1,354 & 169 & 146 & 0.32 \\
WA & Guinea & & & \\
\hline
\end{tabular}

*The average costs do not include the introductory SMS. The platform charges standardized costs for the SMS based on length (number of characters) and country. The average length of completed surveys also varied between Senegal (.97 minutes) and Guinea ( 2 minutes). IVR calls are also charged based on length (e.g. per minute). 
Table A6. The effect of WhatsApp on response rates for engaged contacts

\begin{tabular}{|c|c|c|c|}
\hline & $\begin{array}{l}\text { (1) } \\
\text { All }\end{array}$ & $\begin{array}{c}(2) \\
\text { Guinea }\end{array}$ & $\begin{array}{c}(3) \\
\text { Senegal }\end{array}$ \\
\hline \multicolumn{4}{|c|}{ Panel I. Overall survey response } \\
\hline Contacted via WhatsApp & $\begin{array}{c}-0.075^{* * * *} \\
(0.021)\end{array}$ & $\begin{array}{l}-0.048 \\
(0.084)\end{array}$ & $\begin{array}{c}-0.078^{* * * *} \\
(0.022)\end{array}$ \\
\hline Constant & $\begin{array}{c}0.301^{* * *} \\
(0.053)\end{array}$ & $\begin{array}{c}0.464^{* * *} \\
(0.165)\end{array}$ & $\begin{array}{c}0.286^{* * *} \\
(0.056)\end{array}$ \\
\hline \multicolumn{4}{|c|}{ Panel II. Survey completion } \\
\hline Contacted via WhatsApp & $\begin{array}{l}-0.026 \\
(0.019)\end{array}$ & $\begin{array}{l}-0.048 \\
(0.063)\end{array}$ & $\begin{array}{l}-0.028 \\
(0.020)\end{array}$ \\
\hline Constant & $\begin{array}{c}0.198^{* * * *} \\
(0.048)\end{array}$ & $\begin{array}{c}0.061 \\
(0.124)\end{array}$ & $\begin{array}{c}0.214^{* * * *} \\
(0.051)\end{array}$ \\
\hline$N$ & 1566 & 105 & 1461 \\
\hline
\end{tabular}

Standard errors in parentheses

${ }^{*} p<0.1,{ }^{* *} p<0.05,{ }^{* * *} p<0.01$

The sample includes only respondents that either picked the IVR calls or read the WhatsApp introductory message. The model includes controls for age and gender and age. The comparison group was contacted via IVR

Overall response rate includes all contacts that responded to at least the first question. Completion rate includes all contacts that responded to all questions as expected. 
Figure A1. Percentage of respondents reporting to live outside of Africa by treatment group (in \%)

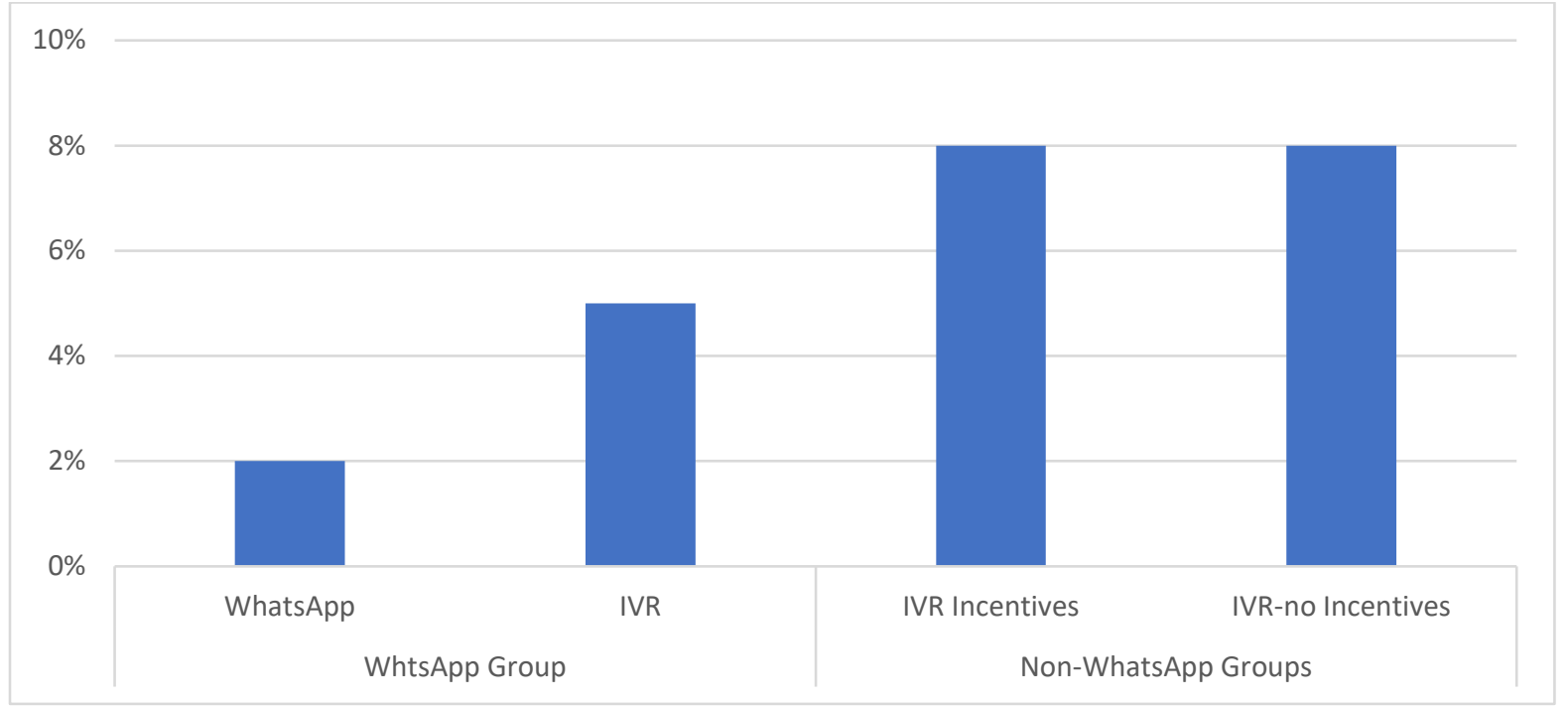

Notes: Respondents were asked where they currently live (1. In their country, 2. In another country in Africa, 3. In another country outside of Africa). The figure includes those who responded that they currently live outside of Africa.

Figure A2: Percentage of respondents reporting an intention to migrate within the next 2 years

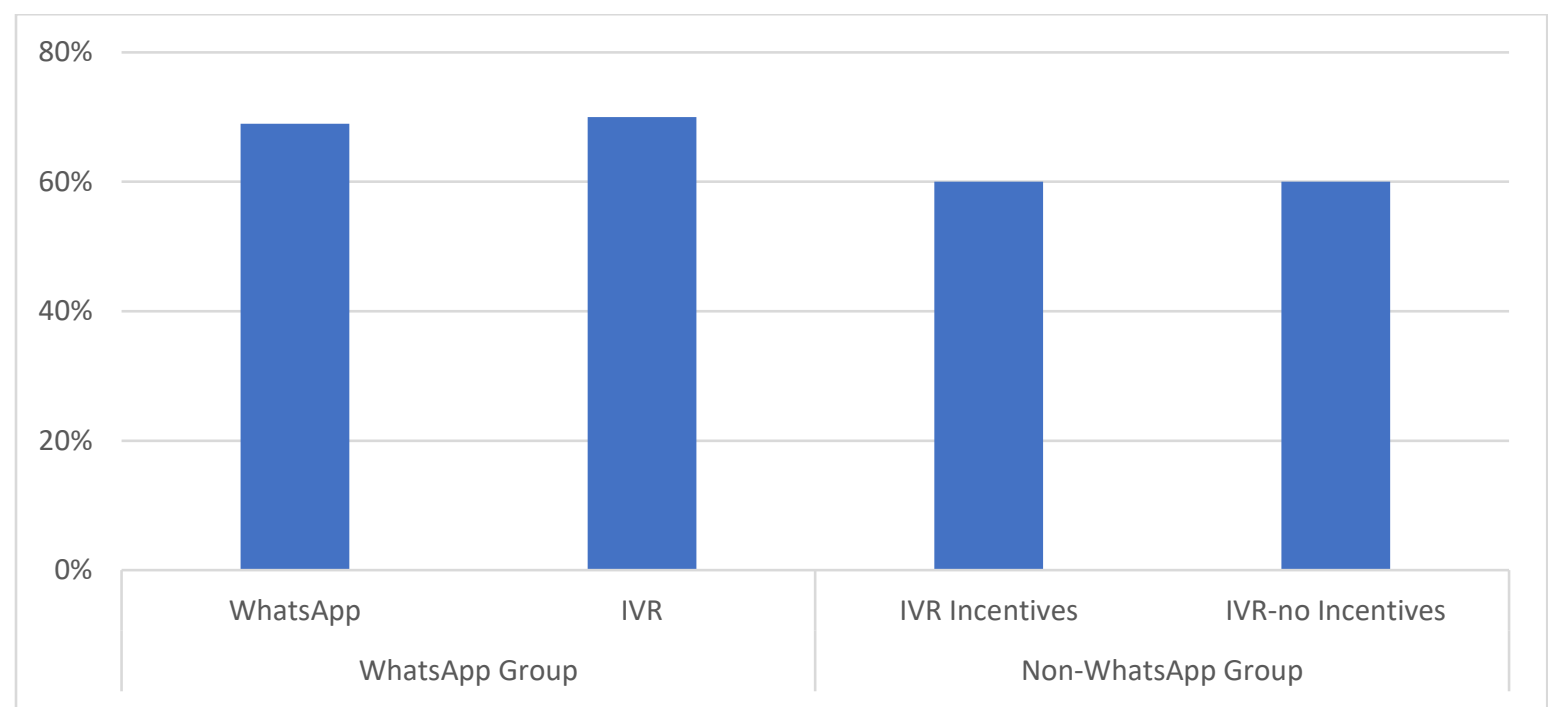

Notes: Respondents that reported being in their country were asked whether they intend to migrate in the next 2 years. The figure includes those that responded that they plan to migrate. 


\section{Table B1: Survey Questionnaire}

\begin{tabular}{|l|l|}
\hline Question & Response options \\
\hline Where do you currently live? & $\begin{array}{l}1=\text { In Senegal } \\
2=\text { In another country in Africa } \\
3=\text { Europe/Outside of Africa }\end{array}$ \\
\hline $\begin{array}{l}\text { Have you attempted to migrate outside of Senegal in the } \\
\text { last two years? }\end{array}$ & $\begin{array}{l}1=\text { Yes } \\
2=\text { No }\end{array}$ \\
\hline $\begin{array}{l}\text { How likely are you to migrate (irregularly) outside of } \\
\text { Senegal/Guinea in the next two years? }\end{array}$ & $\begin{array}{l}1=\text { Never } \\
2=\text { Probable } \\
3=\text { Very Likely }\end{array}$ \\
\hline$\{$ If $2 / 3\}$ How do you plan to travel? & $\begin{array}{l}\text { (=Through regular means } \\
2=\text { Through irregular means }\end{array}$ \\
\hline Did you participate in IOM's research in $2018 ?$ & $1=$ Yes \\
& $2=$ No \\
\hline
\end{tabular}

\section{Table B2: WhatsApp Template Message:}

Hello! Thank you for participating in the IOM's study on migration in 2018 and 2019. We also thank you for accepting to be contacted for a follow-up study. This short survey will take a maximum of 3 minutes and will be in $\{$ Wolof/Susu $\}$. We would like to remind you that your participation is voluntary and with no risks. Would you like to start the survey? Send number for your choice:

1. Yes

2. No 